\title{
Psicologia na Assistência Social e a Atuação por via de Contratos Terceirizados
}

\author{
Catheline Rubim Brandolt ${ }^{1, *}$, Samara Silva dos Santos ${ }^{1}$, \\ Fellipe Coelho-Lima ${ }^{2}$, Roberta Fin Motta ${ }^{3}$
}

\footnotetext{
${ }^{1}$ Universidade Federal de Santa Maria (UFSM), Brasil

${ }^{2}$ Universidade Federal do Rio Grande do Norte (UFRN), Brasil

${ }^{3}$ Pontifícia Universidade Católica do Rio Grande do Sul (PUCRS), Brasil
}

Submissão: 01/04/2019

Primeira decisão editorial: 15/01/2020

Versão final: 04/02/2020

Aceite: $21 / 02 / 2020$

Resumo

O presente estudo tem por objetivo analisar as reverberações identificadas pelas profissionais da Psicologia que atuaram nos serviços do Sistema Único de Assistência Social por meio de contratos terceirizados, entre 2013 a 2017, em um município do interior do estado do Rio Grande do Sul, Brasil. Participaram da pesquisa 12 profissionais, sendo os dados obtidos com base em entrevistas e analisados por meio da técnica da Análise de Conteúdo. Os resultados indicaram acúmulo e desvio de funções, a execução de outras atividades para além das que constava em seus contratos, complementação de renda com um segundo emprego, e principalmente, a fragilização tanto da segurança quanto na saúde da trabalhadora no serviço, gerando adoecimento nas profissionais.

Palavras-chave: trabalho, assistência social, terceirização, psicologia.

\section{Psychology in Social Assistance and the Acting through Outsourced Contracts}

\section{Psicología en la Asistencia Social y la Actuación por vía de Contratos Tercerados}

Abstract

This study aims to present that reverberations were identified by Psychology professionals who worked in the services of the Unified Social Assistance System between 2013 to 2017, in a city in the interior of the state of Rio Grande do Sul, Brazil. For this, 12 professionals participated in the research, being the data obtained from interviews and analyzed based on Content Analysis. The results indicated an accumulation and diversion of duties, the execution of other activities besides those that appeared in their contracts, income supplementation with a second job, and mainly the weakening of both the safety and the health of the worker in the service, generating illness in the professionals.

Keywords: work, social assistance, outsourcing, psychology.
Resumen

$\mathrm{El}$ presente estudio tiene por objetivo analisar las reverberaciones identificadas por las profesionales de la Psicología que actuaron en los servicios del Sistema Único de Asistencia Social entre 2013 a 2017, en un municipio del interior del estado de Rio Grande do Sul, Brasil. Participaron de la investigación 12 profesionales, siendo los datos obtenidos a partir de entrevistas y analizados con base en el Análisis de Contenido. Los resultados indicaron acumulación y desvío de funciones, la ejecución de otras actividades además de las que constaba en sus contratos, complementación de renta con un segundo empleo, y principalmente, la fragilización tanto de la seguridad y la salud de la trabajadora en el servicio, generando la enfermedad profesionales.

Palabras-clave: trabajo, assistencia social, tercerización, psicologia.
* Informações sobre o autor principal:

Rua Coronel Niederauer, no 913, apartamento 406 B, Bairro: Bonfim, Santa Maria (RS),

Brasil, CEP 97015-121.

E-mail: cathelinerb@gmail.com
Como citar esse artigo: Brandolt, C. R., Santos, S. S., Coelho-Lima, F., \& Motta, R. F. (2020). Psicologia na Assistência Social e a Atuação por via de Contratos Terceirizados. Revista Psicologia: Organizações Trabalho, 20(2), 1033-1039. https://doi.org/10.17652/rpot/2020.2.17987 
$\mathrm{Na}$ atual fase do capitalismo, o processo de reestruturação produtiva emerge como resposta à crise do capital em meados dos anos 1970, objetivando recompor os lucros e aumentar o controle, tanto da produção, quanto dos trabalhadores. A partir desse processo, mudanças atingiram as formas de produção e gestão do trabalho, cujas consequências direcionam-se, principalmente, a atingir de forma cada vez mais nefasta a classe trabalhadora $(\mathrm{Na}-$ varro, Maciel, \& Matos, 2017). Nesse âmbito, observa-se uma tendência da precarização do trabalho, gerando uma nova condição de vulnerabilidade social, instituído pela amplificação e institucionalização da instabilidade e da insegurança, expressa pelas novas formas de organização do trabalho (Antunes \& Druck, 2018).

A precarização do trabalho, revela-se uma estratégia de dominação do capital, que tem na terceirização a sua principal forma de controle sobre os processos de trabalho (Druck, 2011; Druck \& Silva, 2014). A terceirização é um fenômeno que pode ser encontrado em praticamente todas as atividades profissionais - nas indústrias, no comércio, nos serviços, nos setores público e privado, seja no ambiente rural ou urbano. Atualmente, ocupa um lugar central nas políticas de organização e gestão do trabalho, inspirada no Toyotismo, o qual serviu como resposta à crise do padrão fordista (Druck, 2016; Druck, Sena, Pinto, \& Araújo, 2018).

Conceitualmente, terceirização corresponde à transferência de parte do processo produtivo de uma empresa (contratante) para outra organização (contratada ou terceirizada) (Filgueiras \& Cavalcante, 2015). Ela move-se pela redução de custos (das organizações e/ou repartições) no mercado do capital ao mesmo tempo em que promove uma reordenação socioespacial do trabalho, resultando não apenas na precarização do mesmo (e.g. enquanto direitos trabalhistas e salários), mas também na fragmentação do coletivo de classe (representação sindical) (Alves, 2011). Essa prática reconfigura as relações capital-trabalho.

No Brasil, a terceirização tem origens especialmente na organização do trabalho rural, por meio do "sistema de gato", com a contratação de trabalhadoras(es) em períodos de safras (processo ainda presente na agricultura atualmente). Tal prática foi utilizada nos primórdios da industrialização brasileira (Druck, 2013; Druck et al., 2018). Todavia, acompanhando os novos contornos do capitalismo contemporâneo, esta prática foi impulsionada no contexto brasileiro, a partir dos anos de 1990, em um cenário marcado pelo processo de globalização da economia e serviços e a adoção das políticas neoliberais. Dentre as medidas adotadas estavam: a abertura comercial para o capital estrangeiro, os processos de privatizações, flexibilização e o recuo do papel do Estado, enquanto regulador do mercado de trabalho e da proteção social, e a redução dos gastos públicos (Pereira, Tassigny, \& Bizzaria, 2017; Yamamoto \& Oliveira, 2010).

Nesse período, políticas sociais assistenciais conquistadas e, muitas delas, em fase de implementação, foram atingidas pela onda neoliberal na economia, distanciando-se, assim, dos preceitos inscritos na Constituição de 1988 (Yamamoto \& Oliveira, 2010). O incentivo à terceirização pode ser identificado desde a reforma do Estado, iniciada em 1995, que defendia uma administração pública espelhada na administração da empresa flexível do regime toyotista. Tal incentivo perpassou os anos 2000, com a Lei de Responsabilidade Fiscal, a qual inibiu a realização dos concursos públicos, visando a redução das despesas com o funcionalismo público. Desse modo, ampliou as modalidades de terceirização na esfera pública, por meio de parcerias, concessões, cooperativas, organizações não-governamentais, organização da sociedade civil de interesse público (Druck, 2016).

Os reflexos desse processo de reforma do Estado brasileiro atingiram, de forma mais acentuada, as políticas assistenciais e, por serem políticas tardiamente efetivadas, tem vi- venciado a precarização e fragilização de investimentos mais intensamente (Pereira et al., 2017). A partir de tais informações, a proposta deste artigo se direciona para o campo da Assistência Social. Para isso far-se-á uma breve contextualização da área.

A Assistência Social, como Política Pública de Proteção Social voltada à garantia de direitos e condições de vida a população, é fruto de um processo que tem como marcos a Constituição Federal de 1988 e a Lei Orgânica da Assistência Social (LOAS) em 1993, que a regulamenta enquanto política de caráter não contributivo. Estes avanços esbarraram-se com a abertura econômica do país, o que permitiu a aplicação de ações fragmentadas, desarticuladas e imediatistas no sistema de Proteção Social. Tal situação ocorre, pois há processos contraditórios movimentando-se conjuntamente. Por um lado, identifica-se os avanços constitucionais, no que tange o reconhecimento de direitos e discussão pública sobre a questão da pobreza e da desigualdade social. Por outro lado, com a adoção do Estado brasileiro às políticas neoliberais, ocorreu a retração desses avanços (Cordeiro, 2018; Couto, Yazbek \& Raichelis, 2017; Oliveira, 2012).

Mesmo diante de um cenário atravessado pelo discurso neoliberal a Assistência Social no país conseguiu produzir avanços legais, como a Política Nacional de Assistência Social (PNAS), em 2004 (MDS, 2005), e a atualização da LOAS por meio da Lei n.12435/2011 - Lei que institui o Sistema Único de Assistência Social (SUAS). Tal sistema operacionaliza a PNAS em todo o território nacional norteando serviços, benefícios e ações socioassistenciais, de caráter permanente ou eventual (Couto et al., 2017).

Ressalta-se que no SUAS configuram-se duas formas de Proteção Social, que se reportam as vulnerabilidades e aos riscos que as famílias e seus membros enfrentam no contexto em que vivem: a Proteção Social Básica (PSB), tendo como equipamento estatal o Centro de Referência de Assistência Social (CRAS) e a Proteção Social Especial (PSE) que abrange os níveis: da média e alta complexidade. A PSE de média complexidade conta com o Centro de Referência Especializado da Assistência Social (CREAS), Centro de Referência Especializado para População em Situação de Rua (Centro-POP) e o Centro-dia. Já a PSE de alta complexidade abrange os Serviços de Acolhimento Institucional; Serviço de Acolhimento em República; Serviço de Acolhimento em Família Acolhedora e Serviço de Proteção em situações de calamidades públicas e de emergências (Ministério do Desenvolvimento Social e Combate à Fome - MDS, 2005; 2014). De acordo com a Tipificação Nacional dos Serviços Socioassistenciais (MDS, 2014), tanto a PSB, quanto a PSE podem contar com a prestação de serviço de Organizações Não governamentais.

Destacam-se, ainda, documentos como a Norma Operacional Básica de Recursos Humanos do Sistema Único de Assistência Social (NOB-RH/SUAS) (2006), a Tipificação Nacional dos Serviços Socioassistenciais (2014), a Norma Operacional Básica (NOB/SUAS), revisada em 2012 (Macedo et al., 2011; Oliveira, 2012), que esclarecem sobre a composição das equipes de referência nos serviços socioassistenciais e a gestão do trabalho na Política de Assistência Social. Na NOB-RH/SUAS a(o) profissional da Psicologia consta como uma das profissões importantes e prioritárias para a composição das equipes disponíveis a população atendida nos dispositivos do SUAS, juntamente com a(o) Assistente Social e técnicos de nível médio (Brasil, 2006; Cordeiro, 2018). Então, a partir desta norma ampliou-se consideravelmente o mercado de trabalho para as(os) psicólogas(os) nesta política.

A partir destes documentos, cabe problematizar o papel das(os) trabalhadoras(es) identificadas(os) como as principais mediadoras(es) na operacionalização dos serviços socioassistenciais, ou seja, tornando-se, assim, a sua principal tecnologia (Pereira et al., 2017; Raichelis, 2011). Ressalta-se que as(os) profissionais 
que atuam nos serviços do SUAS, encontram-se expostas a lógica da precarização do trabalho. Esse aspecto pode ser percebido por meio dos contratos/vínculos empregatícios, nos quais as(os) profissionais, que compõe a equipe mínima de referência, não possuem vínculos permanentes nos serviços, o que contraria a proposta da NOB-RH/SUAS; a rotatividade excessiva; a fragilidade do trabalho das equipes (Macedo et al., 2011; Motta, 2015; Raichelis, 2011; Ribeiro \& Guzzo, 2014). Da mesma forma, tal aspecto encontra-se na precária estrutura institucional ofertada nos serviços do SUAS (Pereira \& Frota, 2017; Pereira et al., 2017).

Conforme dados preliminares do Censo do Sistema Único de Assistência Social (Censo SUAS, 2017), das(os) 95.967 trabalhadoras(es) do CRAS, 61,1\% possuem contratos por vínculos não permanentes. Tal situação também ocorre nos CREAS, por exemplo, onde dos 22.831 profissionais, 41,7\% encontram-se na mesma situação (MDS, 2018). Logo, a(o) trabalhadora(r) da Assistência Social, por mais que ocupe um espaço de valorização no âmbito da política, está atravessada(o) pela fragilidade no mundo do trabalho, sendo exposta(o) bem como convivendo com a flexibilização dos direitos trabalhistas, responsabilização do profissional em relação às capacitações de ensino, dentre outros.

A Psicologia uma das profissões que compõe a equipe de referência nos serviços do SUAS e, no que tange o panorama de expansão da profissão neste contexto, dados do Censo SUAS, apresentam que há cerca de 18.735 psicólogas(os), atuando nos serviços em unidades públicas estatais e gestão do SUAS (serviços que correspondem Proteção Social Básica - PSB e Proteção Social Especial - PSE). Nesse Censo, a Psicologia representa o segundo maior segmento profissional mais frequente nos dispositivos que compõem a rede socioassistencial (MDS, 2018).

Desse modo, a categoria das(os) psicólogas(os) está imersa nas mudanças nas formas de organização e gestão do trabalho, estando exposta a prática da terceirização, contrato temporário e subemprego. Este artigo busca analisar quais reverberações foram identificadas pelas profissionais da Psicologia que atuaram nos serviços do SUAS pormeio de contratos terceirizados, no períodode2013 a 2017, no município do interior do estado do Rio Grande do Sul, Brasil.

\section{Método}

Este estudo é de delineamento descritivo e de abordagem qualitativa. Foram realizadas entrevistas semiestruturadas (compostas por questões abertas e fechadas) com doze (12) profissionais da Psicologia que atuaram em serviços do SUAS entre 2013 a 2017 em um município do interior do Rio Grande do Sul, por meio de contrato terceirizado. Para isso elaborou-se um roteiro com dois blocos de questões: (1) Condições de trabalho e (2) Exercício profissional.

O contato inicial com as participantes ocorreu por meio da técnica da "Bola de Neve", a qual prevê a identificação de informantes-chave, que dão início a coleta de informações e permite que estas possam indicar novos participantes para que uma rede de informações seja constituída. Atinge-se o ponto de saturação na pesquisa quando novas informações não são mais coletadas e repete-se as indicações/ novos participantes (Vinuto, 2014).

Todas as entrevistas foram precedidas de explicação e esclarecimentos e, após a leitura e a assinatura do Termo de Consentimento Livre e Esclarecido (TCLE), elas foram gravadas em áudio e depois transcritas integralmente. Assim, as coletas foram realizadas em locais previamente combinados com as participantes (como: dependências de Instituições de Ensino Superior, consultórios particulares das participantes, restaurante-café e em uma escola).

Esta pesquisa foi aprovada pelo Comitê de Ética em Pesquisa com Seres Humanos da Universidade Federal de Santa Maria (CAEE n89346518.4.0000.5346). A fim de garantir o anonima- to e sigilo, foram adotados letras e números como estratégia de identificação para as participantes (P1, P2, P3...). Adotou-se a mesma lógica de classificação em relação aos serviços assistenciais (S1, S2, S3...). Para análise dos dados optou-se pela Análise de Conteúdo (Bardin, 2010), utilizando análise de conteúdo temática como critério semântico. Nesta pesquisa participaram profissionais de Psicologia, que atuaram no Centro de Referência em Assistência Social - CRAS, Centro de Referência Especializado em Assistência Social - CREAS e Acolhimento Institucional, serviços esses que compõe a rede do município em questão. Ressalta-se que a Política de Assistência Social preconiza em sua rede outros equipamentos para a atuação dentro do Sistema Único de Assistência Social, os quais não compuseram a presente pesquisa, como por exemplo: Centro de Referência Especializado para População em Situação de Rua (Centro-POP), Serviço de Acolhimento em Família Acolhedora e Serviço de Proteção em situações de calamidades públicas e de emergências.

No que se refere às características das participantes, onze (11) são mulheres, e apenas um homem. Desse modo, optamos em utilizar o gênero feminino no decorrer do artigo, haja vista que a maioria das participantes é mulher. A faixa etária situa-se entre 28 a 43 anos. Quanto à forma de ingresso, todas foram submetidas a um processo seletivo em cada empresa terceirizada. Em relação aos contratos com as terceirizadas, nove participantes tiveram a carteira de trabalho assinada ao longo de todo o contrato e três iniciaram suas atuações com contrato de prestação de serviço (como autônomas). Com relação ao tempo em que atuaram como psicólogas nos serviços da Assistência Social, cinco profissionais permaneceram de seis meses a um ano no trabalho, outras três entre um ano e meio a dois anos e, por fim, quatro profissionais relataram terem atuado entre 4 a 5 anos nas respectivas unidades pesquisadas.

Ao longo do artigo, serão exploradas as reverberações identificadas por meio dos relatos das psicólogas em situação de terceirização nos dispositivos ofertados pela Assistência Social, a partir do eixo: A terceirização como estratégia para a precarização social do trabalho: questões sobre o exercício profissional da Psicologia na Assistência Social.

\section{Resultados e Discussão}

\section{A Terceirização como Estratégia para a Precarização Social do Trabalho: o Exercício Profissional em Psicologia na Assistência Social}

Como já apontado, o capitalismo contemporâneo tem na superação da crise fordista a sua origem. O mesmo trouxe consigo transformações que acarretaram na ruptura com o anterior padrão de produção, assim gerando novos modos de trabalho e, também de vida, pautados na flexibilização e precarização do trabalho. Desse modo, trata-se de uma rapidez inédita que Druck (2011) caracteriza pela "volatilidade, efemeridade e descartabilidade sem limites de tudo o que se produz e, principalmente, dos que produzem - os homens e mulheres que vivem do trabalho" (p. 42). Enquanto principal mecanismo para expansão destas novas formas de gestão e organização do trabalho, a terceirização dispara como uma 'epidemia'. O trabalho, e consequentemente a trabalhadora, nesta modalidade é concebido como "polivalente", "multifuncional' e "qualificado", tais características (re)produzem o aumento na intensidade e a exploração da trabalhadora (Antunes, 2015). Ao contextualizar o trabalho realizado pelas entrevistadas na Assistência Social, é impossível não compará-lo com esta definição.

Senra e Guzzo (2012) e Ribeiro e Guzzo (2014) apontam que o campo da Assistência Social tem ampliado o mercado de trabalho para psicólogas, contudo, expõe suas trabalhadoras à 
condições e relações de trabalho precarizadas. Um aspecto apontado pelas participantes, foi o acúmulo de funções. Tal ponto, pode ser exemplificado diante da aceitação pelas profissionais para assumirem à coordenação dos serviços durante o período em que atuaram no SUAS. Esta função, no âmbito da gestão, ao mesmo tempo apresenta desafios, conflitos e novas possibilidades no exercício profissional (Macedo et at., 2011; Motta, 2015). Scisleski e Fernandes (2012) reiteram sobre o aumento e importância da categoria no campo da Assistência, bem como discutem sobre a participação profissional como coordenadoras dos serviços socioassistenciais, assinalando tratar-se de uma responsabilidade duplicada. Isso pode ser encontrado nas próximas falas:

Ã, então eu tinha que atender, ã, a questão da coordenação de coordenar o serviço, de relatórios, de 'eni' coisas que são atribuídos a essa função, e além de fazer o meu trabalho como psicóloga. Então era bem...me sentia sobrecarregada as vezes, era bem complicado, tanto é que eu pedi para sair do cargo. E não era remunerado as funções, era uma remuneração só (P10).

Eu sei que teve dois ou três anos que eu comecei a atuar como coordenadora também. Não pode, né. Mas eu tava como coordenadora e psicóloga (P1).

Conforme consta na NOB-RH/SUAS (2006), a função de coordenação pode ser realizada por uma técnica de nível superior, que tenha experiência em trabalhos comunitários e gestão de programas, projetos e benefícios socioassistenciais, e seja concursada. Entretanto, ao analisar as falas das entrevistadas, percebe-se a existência de contrapontos, principalmente, quando compara-se as duas últimas características citadas, pois a maioria afirmou ter sido convidadas a assumir o cargo, e não possuir anteriormente experiências em cargos de gestão. Com isso, foram conhecendo as atribuições da função no dia-a-dia do serviço. Conforme as falas a seguir:

E aí teve uma reunião, e eles convidaram se eu queria assumir a coordenação. No início eu fiquei com muito medo, com muito medo mesmo, mas aquela...digamos aquele sangue no olho de psicólogo novinho querendo trabalhar, eu disse: então vamo embora! Então eu aceitei (P5).

É que quando a Assistente Social de lá foi demitida, 'P3, tu assume a coordenação?', e eu: 'Assumo!'. Na parte financeira não faria diferença nenhuma, mais em responsabilidade nos relatórios mensais. (...) Era quem levava mijada na reunião mensal. É...nunca teve um treinamento 'é assim que é ser coordenadora' (P3).

Ao deparar com a questão da gestão nos serviços, dois pontos merecem ser mencionados. O primeiro direciona-se ao aspecto da demonstração do reconhecimento e confiança no trabalho destas profissionais para assumirem tal cargo. Motta (2015) visualiza esta atividade como mais uma possibilidade do trabalho psicológico na área. Ademais, reforça a necessidade de espaços formativos (tanto na graduação em Psicologia, quanto em espaços de educação permanente nos serviços). A autora reflete, ainda, a preocupação com a forma como vem ocorrendo a ocupação do cargo de coordenadora pelas profissionais da Psicologia, uma vez que está diretamente ligada a precarização e flexibilização do trabalho. Este é um ponto a ser destacado, uma vez que ele pode gerar sobrecarga, e venha a prejudicar a qualidade do trabalho, principalmente, quando não há uma capacitação ou preparação prévia, ou apoio institucional para tal. Reflexões como essa aparecem de forma subjacente nos relatos das participantes, principalmente, ao analisar a influência do tempo de trabalho (inserção no serviço) com o próprio processo de trabalho. Ou seja, as participantes com tempo de trabalho igual ou inferior a dois anos verbalizaram de forma mais clara aspectos da precarização no próprio processo de trabalho, indicando uma preocupação com assunção de responsabilidades face as prcárias condições de trabalho.

Atrelada esse eixo, destaca-se o problema do desvio de funções. Tal aspecto esteve presente nos relatos das entrevistadas, uma vez que além de ocuparem mais de um posto de trabalho, também se dividiam entre diferentes dispositivos da rede (tanto da rede de Saúde, como a de Assistência Social), fragmentando os seus saberes e suas práticas. Este aspecto é exemplificado nas falas seguintes:

E a princípio eu era para ser contratada ali no S3... todos os dias... todos os dias de manhã né. (...) Só que daí a T3, ela me desviou pra... para essa clínica de doente mental. (...) eu acabei me vendo ali na S3. atuando não como psicóloga. Eu tava mais administrativa ali, do que atuando como uma psicóloga. E porque eu tava me desdobrando entre três, eu era contratada pra uma coisa, e daqui a pouco eu tava sendo desviada (P8).

E daí, um tempo depois (na S2), apareceu de eu poder, assumir o S1 também, como psicóloga. E aí dobrou a minha carga horária e dobrou o meu salário (...) Eu revezava assim, as vezes dias, as vezes turnos, normalmente turnos. Manhã num, tarde noutro (P3).

Algumas participantes relataram que, devido à precária infraestrutura e investimentos nos serviços, tiveram que realizar tarefas que envolveram a higiene e limpeza das dependências físicas dos locais de trabalho. Dentre os aspectos apresentados por Druck (2016), referentes a proliferação da terceirização nos serviços públicos, destacam-se: a falta de investimento e valorização dos serviços, representado também na ausência de insumos de materiais para eles. Diante dessa colocação, notamos que tal situação se reflete nos relatos das profissionais que estiveram na ponta dos serviços, causando incômodo, estresse e revolta. Tais casos podem ser vistos nas falas seguintes:

E era nós mesmos que tinha que puxar a água com rodo/ com vassoura, porque a prefeitura não encaminhava uma equipe pra fazer essa limpeza. Até os banheiros a gente limpava. Então teve um período ali/ uma lacuna um pouco difícil ali. E aí a gente exigiu/ cobrando/ pedindo que...que fosse mudado, que mudasse de lugar (P5).

Às vezes nós tínhamos que fechar o serviço no dia de movimento mais tranquilo né, (...)Nós 'tá gurias, vamo aproveitar e fazer faxina', e aí nos faxinávamos até o banheiro. Quer me ver um dia que eu tava furiosa era esse dia, 'pô não me formei pra isso', mas nós não podia viver num chiqueiro (P6).

Outro ponto a se destacar nas falas das entrevistadas, corresponde a busca por um segundo emprego. Conforme Druck (2013), esta ação torna-se recorrente diante das diversas formas de contratos de trabalhos. Isto demonstra a necessidade de complementar a renda diante dos baixos salários (Cordeiro \& Sato, 2017; Motta, 2015), realizando outras atividades, em horários diversos, acumulando novas tarefas no seu cotidiano.

Complementando Bastos, Gondim e Borges-Andrade (2010) e Macêdo, Heloani e Cassiolato (2010) em suas pesquisas apontam que muitas profissionais da Psicologia possuem mais de uma forma de inserção no mercado de trabalho, combinando trabalho assalariado com o trabalho autônomo. Esse dado transparece a 
fragilidade das condições de trabalho para manter as questões básicas de sobrevivência para as profissionais, mas também para suas famílias. Pode-se observar tal questão nas falas:

Eles não pagam um valor razoável assim que eu acho que dentro da categoria deveria ser um pouco mais, né. Mas então eu acabava buscando fora assim, e tinha essa flexibilidade. Eles nunca nos cobraram que deveria de ser dedicação exclusiva, né. Tanto é que eu tinha $40 \mathrm{~h}$ e eu fazia outras coisas por fora $\operatorname{assim}(\mathrm{P} 10)$.

Eu fazia por fora viagens, como... mas era mais final de semana, ou eu jogava as minhas cargas horárias, porque como eu fiquei só um mês no $\mathrm{S} 1$, depois diminuiu a carga horária de novo, eu jogava as minhas cargas horarias e fazia como uma proposta de uma empresa pra licitação. Então eu viajava Rio Grande do Sul e Santa Catarina. Que daí dava um dinheiro bom (P3).

Ao longo das entrevistas, um ponto sobressaiu: a esfera do adoecimento das profissionais decorrente da experiência do trabalho terceirizado. Navarro e Padilha (2007) e Aquino, Sabóia, Melo, Carvalho e Ximenes (2015), ressaltam que as consequências para a classe trabalhadora, decorrentes das mudanças provocadas pela reestruturação produtiva, refletem não apenas em perdas trabalhistas, mas também no crescente número e variados problemas de saúde relacionados ao trabalho. Segundo, Macedo et al. (2011) contraditoriamente as trabalhadoras que atuam na Assistência Social, e que foram contratadas para desenvolver ações de proteção de sujeitos e famílias em situações de subempregos e desemprego, acabam vivenciando elas mesmas estas condições precarizadas.

Complementando Druck (2013) menciona que a exposição à condições de trabalho precárias e vulneráveis reforça a fragilização, tanto da segurança, como na saúde da trabalhadora no serviço. Filgueiras e Cavalcante (2015), ao abordarem diretamente sobre a terceirização, mencionam que trabalhadoras submetidas a esta estratégia de gestão/organização têm maior tendência a terem desrespeitados seus limites físicos. Este aspecto pode ser percebido nas falas seguintes, corroborando o estudo de Filgueiras e Cavalcante (2015):

(...)eu comecei a me desmotivar, e aí, hoje inconscientemente, refletindo sobre isso, ã, eu digo: eu fiz de tudo para que me demitissem. E eu consegui (...). E então pra mim aquilo foi assim, ô um alívio, assim na hora, eu disse: muito obrigada meu deus, eu já não aguentava mais. O meu físico, eu já não comia, e eu não aguentava, não suportava mais (P7).

Eu comecei a adoecer lá dentro, aí os problemas de lá começaram a me afetar muito, eu realmente fiquei muito doente, ai eu vi que estava no meu limite ali dentro. Apesar de amar o trabalho, o sistema/ a engrenagem que mantinha esse trabalho começou a me adoecer (P6).

Cabe ressaltar que, por meio da terceirização, as novas relações de trabalho encontram um terreno fértil para gerar e/ou aflorar o sofrimento e adoecimento dos sujeitos. Navarro et al. (2017) afirmam que devido ao uso dessa prática como estratégia para barateamento dos custos com o trabalho, propicia-se o crescimento de adoecimentos na classe trabalhadora. Paparelli, Sato e Oliveira (2011) apontam que os elementos presentes na organização e ambiente de trabalho influenciam a saúde mental dos trabalhadores. Franco, Druck e Seligmann-Silva (2010) ampliam a discussão, abordando sobre a dimensão psíquica dessas profissionais. Aspectos como esgotamento, desestabilização e desgaste emocional, além de sentimentos de desproteção e de ruptura de ética, são alguns exemplos destacados na pesquisa destes autores. Exemplifica-se nas seguintes falas as experiências de adoecimento das participantes:

Daí quando eu vi eu já tava, vamo dizer, que afundada naquilo, já totalmente mergulhada naquilo e não via mais nada, (...) porque aquilo me consumia demais, tanto psicologicamente quanto, principalmente psicologicamente. E fisicamente também (P8).

Então, teve dois anos de trabalho que psicologicamente era muito difícil. Tanto é que chegava férias / final do ano eu já pensava aonde eu poderia encaminhar o currículo. Os dois últimos anos de férias, eu encaminhei vários currículos porque a intenção era realmente era sair dali (P5).

Sobre o desgaste emocional, referido nos exemplos anteriores, Paparelli et al. (2011) o definem como "a presença de perda ou de transformações negativas na subjetividade, nas capacidades e faculdades humanas" (p.125). Para Franco et al. (2010), tal desgaste é permeado pelo uso intencional da psicológica no ambiente de trabalho, a fim de obter a submissão às imposições de produtividade ou provocar a demissão. Com base nesses fatos, reitera-se a importância de abordar a questão do adoecimento decorrente do cotidiano nos serviços terceirizados, para além de pesquisas com foco na legislação trabalhista e nas condições de trabalho. É necessário que se possam explorar o reflexo dessas características da organização do trabalho contemporâneo nas profissionais que estão à frente dos locais de trabalho.

É importante considerar que, desde a década de 1970-1980, há estudos no campo da Psicologia no âmbito da saúde do trabalhador, especialmente nas relações entre saúde mental e trabalho. Há, entretanto, como apontam Cordeiro e Sato (2017), uma relativa escassez de estudos que envolvem as profissionais de Psicologia. Neste estudo, em síntese, são apresentadas manifestações decorrentes do aumento da exploração da força de trabalho assalariada, que encontra na terceirização potência para flexibilizar e precarizar também as relações e atuação enquanto profissionais de nível superior. Contudo, embora a proposta deste mecanismo seja atingir o conjunto de trabalhadoras, enfraquecendo as instâncias de controle e proteção social, assim como Raichelis (2011), observa-se a necessidade de discutir estratégias de organização coletiva para enfrentar tais processos. Como exemplifica, Motta (2015) participações em atividades do Sistemas Conselhos (Conselho Federal de Psicologia [CFP], do Conselho Regional de Psicologia [CRP], do Centro de Referência Especializado em Psicologia e Políticas Públicas [CREPOP]), Controle Social (Pré e Conferências), entre outras instâncias deliberativas, podem propiciar discussões e ações conjuntas na tentativa de refletir sobre o impacto deste processo. Por meio desses espaços coletivos é possível ressignificar o trabalho das(os) psicólogas(os)na área da Assistência Social, transformando-o em espaços de luta e resistência.

\section{Considerações Finais}

A terceirização, destaca-se como uma ferramenta das novas formas de gestão e organização do trabalho, que permite o assujeitamento e exposições das profissionais de Psicologia às precárias condições de trabalho e relações de emprego. Ao mesmo tempo, é uma modalidade a qual a maioria das trabalhadoras desconhece seus sentidos e perspectivas análogas de trabalho. Tal estratégia, está inserida nas Políticas Públicas, desde a proposta de reforma na Administração Pública, a partir de 1990.

Ao pensar a adoção da terceirização no campo da Assistência Social é imperativo perceber o quanto tal prática apoia e 
auxilia na promoção da lógica de enxugamento do Estado. Essa lógica política é utilizada pelos representantes do Estado para retirar-se de espaços na esfera pública para que a iniciativa privada passe a ocupá-los, apoiando uma série de medidas direcionadas ao desmantelamento e o desmonte da proteção social.

Com base nos relatos das participantes, foi possível identificar que decorrente de seus contratos terceirizados, as profissionais se depararam com o acúmulo e desvio de funções, bem como a execução de outras atividades, para além das que constava em seus contratos, e a necessidade de buscar um segundo emprego para complementar a renda. Além disso, as profissionais mencionaram reflexos também em sua saúde, gerando sofrimento e adoecimento das profissionais, tanto na dimensão física como psíquica.

Raichelis (2011) destaca a necessidade de atentar para as condições de trabalho das profissionais do SUAS, destacando que o adoecimento físico e mental, desencadeado pela dinâmica institucional, ainda é uma questão nova enquanto ponto de estudo nas pesquisas. Desse modo, nos convocamos a modestamente apresentar sua aparição enquanto resultados dos relatos que afetaram a permanência e continuidade do desenvolvimento do exercício profissional das psicólogas nos serviços do SUAS.

Por fim, diante desse cenário, as(os) psicólogas(os) estão inseridas e submetidas às características da organização do trabalho sob a égide das políticas assistenciais do Estado. Há a necessidade das profissionais de Psicologia em se reconhecerem como pertencentes à classe trabalhadora assalariada, que precisa construir mecanismos de participação nas estratégias de organização e execução do trabalho nas instituições responsáveis pelas políticas sociais assistenciais. E isso, certamente, tende a romper o estereótipo tradicional da categoria, visto como liberal e apolítico, procurando resgatar a dimensão política no cotidiano da profissão, baseada em ações críticas sobre a realidade e na compreensão da necessidade da articulação, tanto entre as próprias psicólogas, quanto em direção às outras categorias profissionais. Assim, espera-se que deste estudo possam suscitar inquietações para que outras pesquisas venham a ser desenvolvidas com o viés de retratar o trabalho terceirizado nas atividades profissionais em Psicologia no campo das políticas sociais assistenciais, o qual merece ser explorado e aprofundado.

\section{Referências}

Alves, G. (2011). terceirização e acumulação flexível do capital. Estudos sociológicos, 16(31), 409-420. Recuperado de https://periodicos.fclar.unesp.br/estudos/ article/view/4513/3960

Antunes. R. (2015). A sociedade da terceirização total. Revista da ABET, 14(1), 6-14. Recuperado de http://periodicos.ufpb.br/ojs/index.php/abet/article/ view/25698/13874

Antunes, R. \& Druck, G. (2018). A precarização do trabalho como regra. Em R. Antunes (Ed.), O privilégio da servidão: o novo proletariado de serviços na era digital (pp. 173-190). 1.ed. São Paulo: Boitempo.

Aquino, C. A. B. de, Sabóia, I. B. de, Melo, P. B. de, Carvalho, T. A. de, \& Ximenes, V. M (2016). terceirização e saúde do trabalhador: uma revisão da literatura nacional. Revista Psicologia: Organizaçoes e trabalho, 16(2), 130-142. https://doi.org.10.17652/rpot/2016.2.660

Bardin, L. (2010). Análise de conteúdo. Lisboa: Edições 70.

Bastos, A. V. B., Gondim, S. M. G., \& Borges-Andrade, J. E. (2010). O psicólogo brasileiro: sua atuação e formação profissional. $\mathrm{O}$ que mudou nestas últimas décadas. Em O. H. Yamamoto \& A. L. F. Costa (Eds.), Escritos sobre a profissão de psicólogos no Brasil (pp. 255-270). Natal: EDUFRN.

Brasil (2006). Norma operacional básica de recursos humanos do SUAS - NOBRH/ SUAS. Resolução do CNAS no 269, de 13 de dezembro de 2006, publicada no D.O.U. em 26 de dezembro de 2006. Brasília.

Cordeiro, M. P. (2018). O Sistema Único de Assistência Social (SUAS): uma breve introdução. Em M. P. Cordeiro, B. Svartman, \& L. V. Souza (Eds.), Psicologia na Assistência Social: um campo de saberes e práticas (pp. 63-80). São Paulo: Instituto de Psicologia.

Cordeiro, M. P., \& Sato, L. (2017). Psicologia na política de assistência social: trabalho em um "setor terceirizado". Estudos de Psicologia (Campinas), 34(1), 41-52. https://doi.org/10.1590/1982-02752017000100005
Couto, B. R., Yazbek, M. C., \& Raichelis, R. (2017). A Política Nacional de Assistência Social e o Suas: apresentando e problematizando fundamentos e conceitos. Em B. R. Couto, M. C. Yazbek, M. O. da S. Silva, \& R. Raichelis (Eds.), O Sistema Único de Assistência Social no Brasil: uma realidade em movimento (pp. 61-94). $5^{\text {a }}$ ed. revisada e atualizada. São Paulo: Cortez.

Druck, G. (2011). Trabalho, precarização e resistências. Caderno CRH, 24(n.spe), 37-57. https://doi.org/10.1590/S0103-49792011000400004

Druck, G. (2013). A precarização social do trabalho no Brasil: alguns indicadores. In.: R. Antunes (Ed.). Riqueza e Miséria do trabalho no Brasil II (pp. 55-73). São Paulo: Boitempo.

Druck, G. (2016). A terceirização na saúde pública: formas diversas de precarização do trabalho. Revista Trabalho, Educação e Saúde, 14(supl.1), 15-43. https:// doi.org/10.1590/1981-7746-sol00023

Druck, G., Sena, J., Pinto, M. M., \& Araújo, S. (2018). A terceirização no serviço público: particularidades e implicações. Em A. G. Campos (Ed.), Terceirização do trabalho no Brasil: novas e distintas perspectivas para o debate (pp. 113-141). Brasília: Ipea.

Druck, G., \& Silva, J. B. (2014). Precarização, terceirização e Ação sindical. Em G. N. Delgado \& R. J. M. B. Pereira (Eds.), Trabalho, Constituição e Cidadania: a dimensão coletiva dos direitos sociais trabalhistas (pp. 31- 45). São Paulo: LTr.

Filgueiras, V. A., \& Cavalcante, S.M. (2015). terceirização: debate conceitual e conjuntura política. Revista ABET, 14(1), 15-36. Recuperado de http://www. periodicos.ufpb.br/ojs/index.php/abet/article/view/25699/13875

Franco, T., Druck, G., \& Seligmann-Silva, E. (2010). As novas relações de trabalho, o desgaste mental do trabalhador e os transtornos mentais no trabalho precarizados. Revista Brasileira de Saúde Ocupacional, 35(122), 229-248. https://doi.org/10.1590/S0303-76572010000200006

Lei no 12.435 (2011, 6 de julho). Altera a Lei no 8.742, de 7 de dezembro de 1993, que dispõe sobre a organização da Assistência Social. Brasília, DF: Presidência da República. Recuperado de http://www.planalto.gov.br/ccivil 03/ Ato20112014/2011/Lei/L12435.htm

Macedo, J. P, Sousa, A. P., Carvalho, D. M., Magalhães, M. A., Sousa, F. M. S., \& Dimenstein, M. (2011). O psicólogo brasileiro no SUAS: quantos somos e onde estamos? Psicologia em Estudo, 16(3), 479-489. https://doi.org/10.1590/ $\underline{\text { S1413-73722011000300015 }}$

Macêdo, K. B., Heloani, R., \& Cassiolato, R. (2010). O psicólogo como trabalhador assalariado: setores de inserção, locais, atividades e condições de trabalho. Em A. V. B. Bastos, \& S. M. G. Gondim (Eds.), O trabalho do psicólogo no Brasil: um exame à luz das categorias da psicologia organizacional e do trabalho (pp. 131 - 150). Recurso eletrônico. Porto Alegre: ARTMED.

Ministério do Desenvolvimento Social e Combate à Fome (2005). Política Nacional de Assistência Social-PNAS/2004 e Norma Operacional Básica - NOB/SUAS. Brasília. Recuperado de http://www.mds.gov.br/webarquivos/publicacao/ assistencia social/Normativas/PNAS2004.pdf

Ministério do Desenvolvimento Social e Combate à Fome (2012). Norma Operacional Básica do Sistema Único de Assistência Social (NOB/SUAS). Brasília. Recuperado de https://www.mds.gov.br/webarquivos/public/NOBSUAS 2012.pdf

Ministério do Desenvolvimento Social e Combate à Fome (2014). Tipificação Nacional de Serviços Socioassistenciais. Brasília. Recuperado de https://www.mds. gov.br/webarquivos/publicacao/assistencia social/Normativas/tipificacao. pdf

Ministério do Desenvolvimento Social e Combate à Fome (MDS) (2018). Censo SUAS 2017. Recuperado de http://aplicacoes.mds.gov.br/snas/vigilancia/ index2.php

Motta, R. (2015). O trabalho das (os) psicólogas (os) no SUAS: materializando a assistência social enquanto politica social pública (Doutorado em Psicologia). Pontifícia Universidade Católica do Rio Grande do Sul.

Navarro, V. L., Maciel, R. H., \& Matos, T. G. R. (2017). A questão do trabalho no Brasil: uma perspectiva histórica a partir do desenvolvimento industrial. Em M. C. Coutinho, M. H. Bernardo, \& L. Sato (Eds.), Psicologia Social do Trabalho (pp. 15-48). Petrópolis: Vozes.

Navarro, V. L., \& Padilha, V. (2007). Dilemas do trabalho no capitalismo contemporâneo. Psicologia \& Sociedade, 19(spe), 14-20. https://doi.org/10.1590/ $\underline{\mathrm{S} 0102-71822007000400004}$

Oliveira, I. F. O. (2012). Os desafios e limites para a atuação do psicólogo no SUAS. Em L. R. Cruz \& N. Guareschi (Eds.), O psicólogo e as Políticas Públicas de Assistência Social (pp. 35-51). Petrópolis: Vozes.

Paparelli, R.; Sato, L., \& Oliveira, F. de (2011). A Saúde Mental relacionada ao trabalho e os desafios aos profissionais da saúde. Revista Brasileira de Saúde Ocupacional, 36(123), 118-127. https://doi.org/10.1590/S030376572011000100011

Pereira, M. E. R., \& Frota, M. H. de P. (2017). terceirização na Política de Assistência Social: ouvindo os trabalhadores. Textos \& Contextos (Porto Alegre), 16(1), 188-204. https://doi.org/10.15448/1677-9509.2017.1.24612

Pereira, M. E. R., Tassigny, M. M., \& Bizzaria, F. P A. (2017). terceirização e Precarização do Trabalho na Política Pública de Assistência Social. Revista Administração Pública e Gestão Social, 9(3), 171-183. https://doi.org/10.21118/ apgs.v1i3.1321 
Raichelis, R. (2011). O trabalho e os trabalhadores do SUAS: o enfrentamento necessário na Assistência Social. Em Ministério do Desenvolvimento Social e Combate à Fome (Ed.), Gestão do trabalho no âmbito do SUAS: uma contribuição necessária (pp. 39-66). Brasília: MDS.

Ribeiro, M. E., \& Guzzo, R. S. L. (2014). Psicologia no Sistema Único de Assistência Social (SUAS): reflexões críticas sobre ações e dilemas profissionais. Pesquisas e Práticas Psicossociais, 9(1), 83-96. Recuperado de http://www.seer. ufsj.edu.br/index.php/revista ppp/article/view/837/651

Senra, C. M. G., \& Guzzo, R. S. L. (2012). Assistência Social e Psicologia: sobre as tensões e conflitos do psicólogo no cotidiano do serviço público. Psicologia e Sociedade, 24(2), 293-299. https://doi.org/10.1590/S010271822012000200006

Scisleski, A., \& Fernandes, V. (2012). Além das fronteiras da Psicologia, o estrangeiro: a coordenação. Em L. R. Cruz \& N. Guareschi (Eds.), O psicólogo e as Políticas Públicas de Assistência Social (pp. 113-124). Petrópolis: Vozes.

Vinuto, J. (2014). A amostragem em bola de neve na pesquisa qualitativa: um debate em aberto. Revista Temáticas, 22(44), 203-220. Recuperado de https:// www.ifch.unicamp.br/ojs/index.php/tematicas/article/view/2144/1637

Yamamoto, O. H., \& Oliveira, I. F. de (2010). Política Social e Psicologia: uma trajetória de 25 anos. Psicologia: Teoria e Pesquisa, 26(n.spe.), 9-24. https://doi. org/10.1590/S0102-37722010000500002 